\title{
Posterior reversible encephalopathy syndrome complicated with subarachnoid hemorrhage in an eclamptic pregnant patient: case report
}

\author{
Dan $\mathrm{Hu}^{1}$, Jing Xiong ${ }^{1}$, Yunfei Zha ${ }^{2}$ and Zhaohui Zhang ${ }^{1 *}$ (1)
}

\begin{abstract}
Background: Posterior reversible encephalopathy syndrome (PRES) is a neurotoxic condition which comprises various neurological symptoms. This syndrome could be complicated by intracranial hemorrhage including subarachnoid hemorrhage (SAH). However, SAH is rarely seen in eclamptic patients with PRES.

Case presentation: A 34-weeks-pregnant woman at the age of 33 was admitted to the obstetrics department because of an episode of generalized tonic-clonic seizure. Before the seizure, the patient had a headache and was found to have an abnormal systolic blood pressure of $160 \mathrm{mmHg}$. On admission, systolic and diastolic blood pressures were up to 182 and $99 \mathrm{mmHg}$, respectively. Emergent cesarean section was then performed. On hospital day (HD) 2, cranial non-contrast computed tomography (CT) revealed the existence of SAH. Multiple areas of high signals on T2-weighted and fluid attenuated inversion recovery (FLAIR) sequences were shown by cranial magnetic resonance imaging (MRI) performed 2 days later. CT-angiography studies didn't reveal intracranial aneurysm. After anti-hypertensive treatment, arterial blood pressure of the patient was gradually tapered to normal values. Eventually, the patient was discharged without any residual symptoms.

Conclusions: SAH is a rare complication of PRES in eclamptic patients. In patients with PRES, occurrence of SAH is related to increased morbidity and mortality especially when the hemorrhage is diffuse or massive. Our patient had a minor hemorrhage. The good prognosis might also be due to immediate elimination of the risk factor of PRES by emergent delivery.
\end{abstract}

Keywords: Posterior reversible encephalopathy syndrome, Subarachnoid hemorrhage, Eclampsia

\section{Background}

Posterior reversible encephalopathy syndrome (PRES) is a distinct clinico-radiological disease entity typically comprising a variety of symptoms such as headache, visual loss, impaired consciousness and epileptic seizures. This syndrome mainly occurs in the setting of hypertension, sepsis, eclampsia, autoimmune diseases or immunosuppressive therapy [1-3]. Cerebral imaging often present as a unique pattern of subcortical white matter edema with typical parietal-occipital predominance [4].

\footnotetext{
* Correspondence: zhzhqing1990@163.com

'Department of Neurology, Renmin Hospital of Wuhan University, Jiefang

Road 238, Wuchang District, Wuhan 430060, China

Full list of author information is available at the end of the article
}

Recognition of subarachnoid hemorrhage as an atypical imaging appearance has recently increased $[5,6]$. There are, however, few reports of such an occurrence in eclamptic patients with PRES. Here, we report a case of 34-weeks-pregnant woman who developed eclampsia and PRES as well as subarachnoid hemorrhage.

\section{Case presentation}

A 34-weeks-pregnant woman at the age of 33 was admitted to the obstetrics department after having an episode of generalized tonic-clonic seizure accompanied by headache and transient blurred vision. 2 days before the occurrence of seizure, the patient had a headache which was relieved significantly after rest. Abnormal systolic

(c) The Author(s). 2018 Open Access This article is distributed under the terms of the Creative Commons Attribution 4.0 International License (http://creativecommons.org/licenses/by/4.0/), which permits unrestricted use, distribution, and 
blood pressure of $160 \mathrm{mmHg}$ was discovered in the latest antenatal appointment. On admission, systolic and diastolic blood pressures were 182 and $99 \mathrm{mmHg}$, respectively [mean arterial pressure (MAP) 127]. On neurologic examination the patient was conscious. The laboratory studies disclosed leukocyte $12.9 \times 10^{9} / \mathrm{L}$ (reference $3.5-9.5 \times 10^{9} / \mathrm{L}$ ) and lactate dehydrogenase (LDH) $282 \mathrm{U} / \mathrm{L}$ (reference 114-240 U/L). Clotting tests showed elevated levels of plasma D-dimer $3.61 \mathrm{mg} / \mathrm{L}$ (reference $0-0.55 \mathrm{mg} / \mathrm{L}$ ) and fibrinogen $4.21 \mathrm{~g} / \mathrm{L}$ (reference $2-4 \mathrm{~g} / \mathrm{L}$ ). The platelet count, the red blood cell count and levels of serum liver enzymes were all normal. Then, the patient was transferred to the operating room for an emergent cesarean section. The baby's APGAR scores at $1 \mathrm{~min}, 5 \mathrm{~min}$, and $10 \mathrm{~min}$ were 7,8 , and 8 , respectively. On hospital day (HD) 2 , the patient complained of abdominal pain without any other discomforts. Cranial non-contrast computed tomography (CT) revealed subarachnoid hemorrhage (SAH) in the right parietal-occipital sulci and hypodensities in the left frontal and parietal lobes (Fig. 1).Cranial magnetic resonance imaging (MRI) performed 2 days later showed multiple areas of high signals on T2-weighted and fluid attenuated inversion recovery (FLAIR) sequences, involving the left cerebral peduncle, the bilateral parietal and the left frontal subcortical regions (Fig. 2). There were no abnormal signals in the corresponding regions on diffusion weighted imaging (DWI) (Fig. 2). MRI susceptibility weighted imaging (SWI) confirmed the existence of SAH (Fig. 2). CT-angiography test performed thereafter was normal except for a subtle enlargement at the origin of the right posterior communicating artery (Fig. 3). During the hospitalization, the patient received oral anti-hypertensive drugs (Adalat, $30 \mathrm{mg}$ per day) and arterial blood pressure was gradually tapered to normal range. When she was transferred to the department of neurology, no symptoms were observed and the neurologic examination was normal. About a few days later, a follow-up brain MRI (data not shown) showed no abnormality. Without use of any anti-hypertensive and anti-epileptic treatment, the patient was discharged eventually with normal blood pressure.

\section{Discussion and conclusions}

PRES was first described by Hinchey and colleagues in 1996 [3]. Clinically, this disease is characterized by acute or subacute onset of neurological symptoms including altered mental state, epileptic seizures, headache, visual disturbances and focal neurological deficit (eg, hemiparesis, aphasia, and even myelopathic symptoms) [7]. Our patient presented with the constellation of symptoms including headache, blurred vision, and seizure. It has been proposed that generalized seizure is related to the focal abnormality of parietal-occipital lobes [2]. For our patient, MRI showed abnormal signals in the bilateral parietal subcortical regions, which might be responsible for occurrence of seizure.

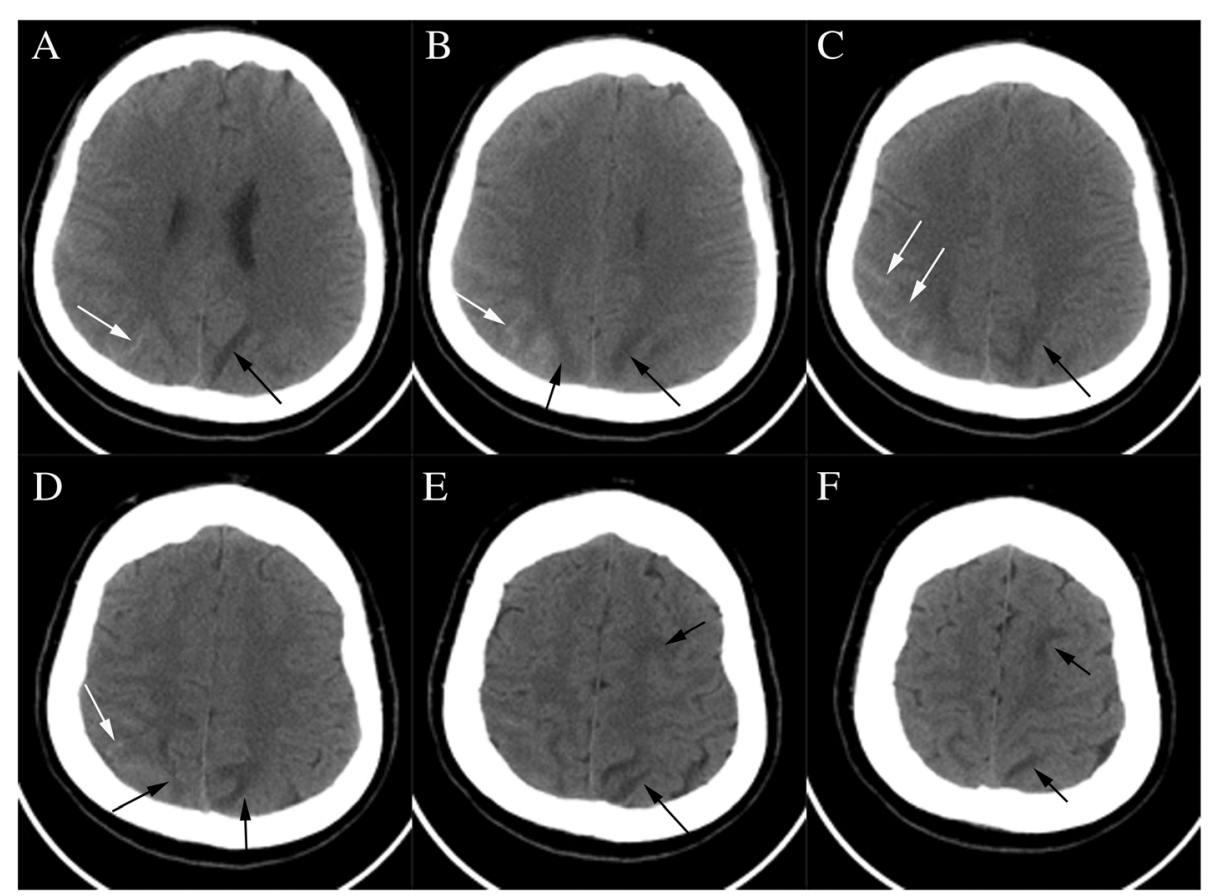

Fig. 1 CT scan (a-f) shows lesions with hyperdensity in the parietal-occipital sulci (white arrows) and hypodensity in the left frontal and parietal lobes (black arrows) 


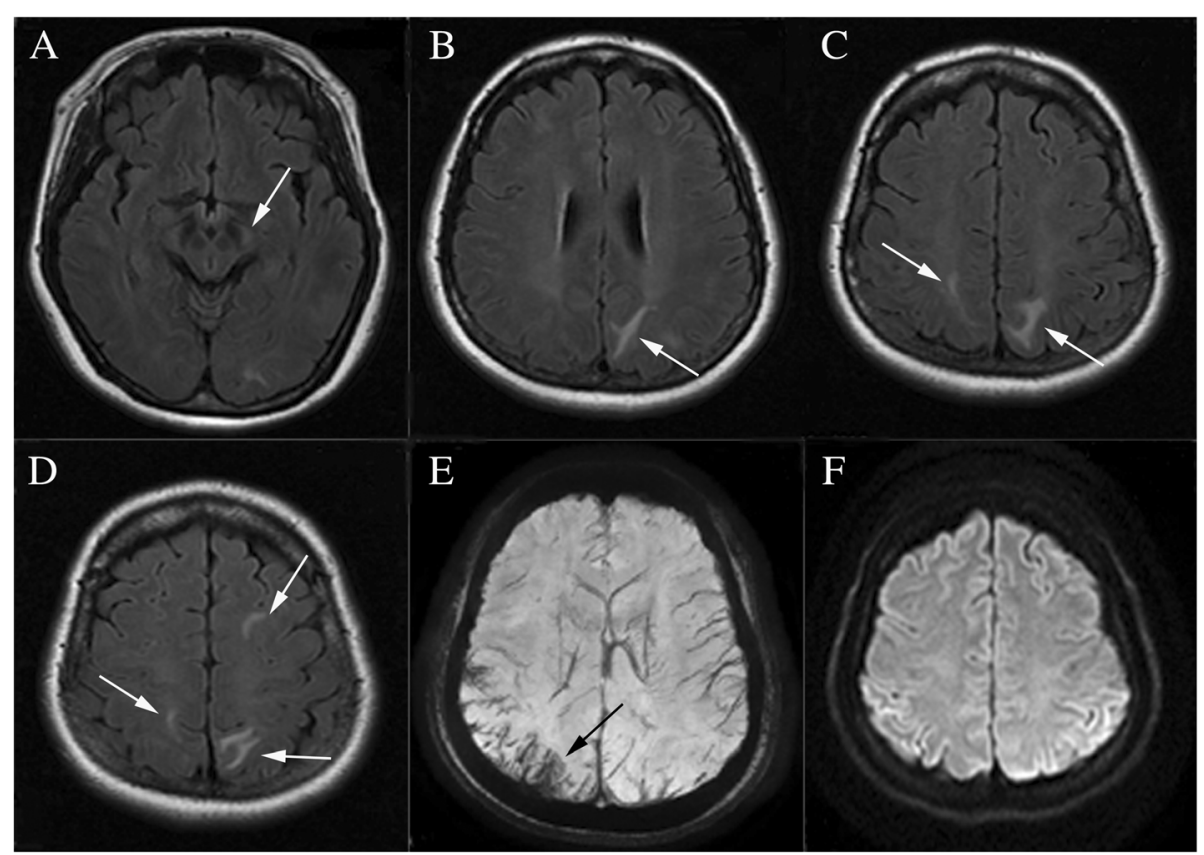

Fig. 2 Axial FLAIR (a-d) demonstrates PRES lesions involving multiple regions (white arrows). SWI (e) reveals low signals in the right parietaloccipital sulci. There are no abnormal signals in DWI (f)

The pathophysiology of PRES remains controversial. Rapid development of hypertension exceeds the upper limit of cerebral blood flow autoregulation, which leads to impaired cerebral autoregulation and hyperperfusion. Subsequently, the blood-brain barrier (BBB) breaks down, followed by extravasation of fluid and plasma proteins into the brain parenchyma [8]. Furthermore, the posterior head region is particularly affected because of poor sympathetic innervation in the posterior fossa. Another hypothesized mechanism involves endothelial dysfunction and vasoconstriction occurring secondary to systemic toxicity in eclampsia and sepsis, which are the common precipitants of PRES. Release of cytokines such as interleukin (IL)-1 and tumor necrosis factor (TNF- $\alpha$ ) causes endothelial cell activation and damage, resulting in vasoconstriction and hypoperfusion [8-10]. It has been demonstrated that PRES imaging appearance commonly follows a watershed distribution [11]. Interestingly, acute hypertension without exceeding the upper limit of cerebral blood flow autoregulation (140$150 \mathrm{mmHg}$ ) could also lead to endothelial dysfunction in certain circumstances [12]. At least in the setting of eclampsia, however, endothelial dysfunction might contribute more to the development of PRES than hypertension, since there was no significant difference of the average MAP between the eclamptic patients with PRES and those without [13].

Radiologically, PRES typically presents as focal vasogenic edema and the posterior parietal-occipital white matter is commonly affected. Frequent frontal and

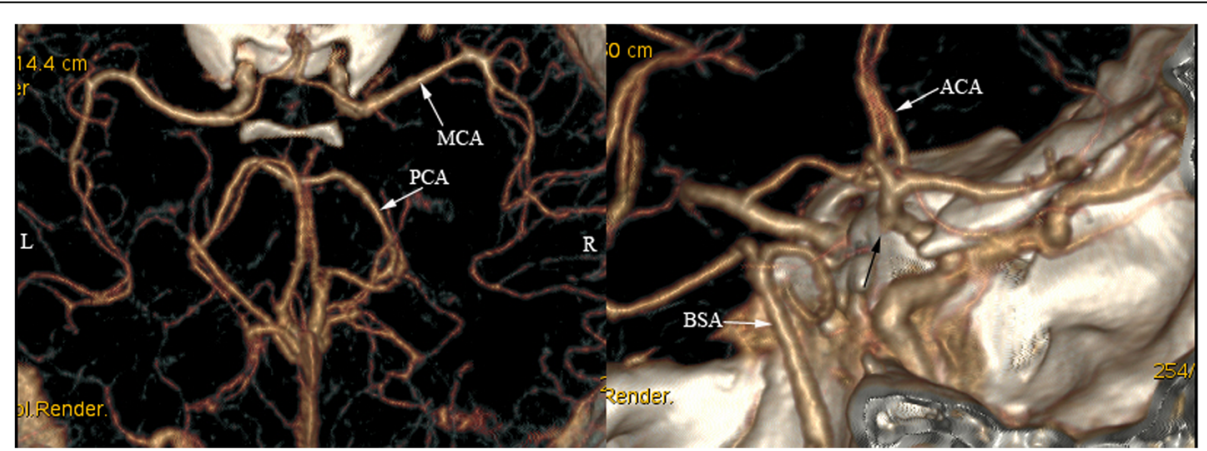

Fig. 3 CTA shows a subtle enlargement at the origin of the right posterior communicating artery (black arrow). L: Left; R: Right; ACA: Anterior cerebral artery; MCA: Middle cerebral artery; PCA: Posterior cerebral artery; BSA: Basilar artery 
temporal lobe involvement has also been reported [14]. Atypical manifestations include the location of lesions in the cerebellum, basal ganglia and brainstem [15]. MRI of our patient showed abnormal T2 and FLAIR signals in the left cerebral peduncle except for the typical locations. In patients with eclampsia, the involvement of atypical brain regions might be explained by the relatively significant impact of cytokine mediated endothelial dysfunction with respect of hypertension on the development of BBB breakdown [13].

Intracranial hemorrhage is common in PRES, which has been reported with an incidence ranging from 9 to $33 \%$ [16-18]. As for the types of intracranial hemorrhage, SAH is relatively less common than intraparenchymal hemorrhage. Notably, the blood amount of SAH in PRES is mostly minimal or moderate and basal cisterns are usually spared, which is distinct from that in cases of aneurysmal rupture [5]. PRES-related hemorrhage is usually to be observed in patients with eclampsia, sepsis/recent infection, allogeneic bone marrow transplantation and those undergoing therapeutic anticoagulation [5, 12, 19]. By contrast, hypertension does not appear to be a prerequisite for the occurrence of hemorrhage [12]. The mechanism behind hemorrhage in PRES is not fully elucidated. It has been proposed that hemodynamic disturbances, endothelial dysfunction, blood brain barrier breakdown and abnormal coagulation profile might play roles in the development of hemorrhage in the setting of PRES [5]. Voetsch et al. [20] reported a case of PRES which is caused by $\mathrm{SAH}$-associated vasospasm. In that case, the blood of SAH presented as a thick clot in the right Sylvian fissure and cerebral angiogram revealed a wide-necked $3 \mathrm{~mm}$ right middle cerebral artery (MCA) aneurysm. Aneurysmal SAH-induced PRES was also reported in another literature [21]. All of the reported patients manifested as diffuse acute SAH in basal cisterns resulting from a ruptured anterior communicating artery aneurysm. In contrast, our patient only showed a minor $\mathrm{SAH}$ at the cerebral convexities and subsequent CT-angiography studies did not show intracranial aneurysm. Thus, SAH was more likely to be a complication rather than a cause of PRES in our case. Reversible cerebral vasoconstriction syndrome (RCVS) is clinically characterized by thunderclap headaches. Patients with RCVS could also present with seizures and focal neurological deficits similar to that in PRES. Some of the cases are even accompanied by SAH and PRES [22]. However, diffuse segmental vasoconstrictions of the cerebral arteries, the radiological characteristic of RCVS, were not found on CT-angiography in our case.

Additionally, parenchymal edema was usually located in the ipsilateral cerebral lobe with respect to SAH in the eclamptic patients with PRES [5]. In our case, however, parenchymal edema predominantly occurred in the cerebral lobe contralateral to $\mathrm{SAH}$, which is rarely seen in these cases. To our knowledge, only one reported eclamptic patient developing PRES presented with this discordant location rediologically [5].

Generally speaking, PRES has a favorable prognosis and the disorder is reversible when the predisposing factors are treated. However, it has been identified that the clinical outcome in patients with PRES is related to multiple factors including intracranial hemorrhage [23]. Hemorrhage appears to lead to increased morbidity and mortality, while it is difficult to determine the relationship in cases of minor hemorrhage [19, 23]. Our patient had a complete resolution of symptoms with a small amount of SAH, which might be associated with emergent delivery.

In the present paper, we described a case of an eclamptic patient who was diagnosed with PRES and SAH. It is rare for PRES-related SAH to occur in pregnant patients with eclampsia. This case provides us with information regarding the diagnosis, treatment, and prognosis of this kind of patients.

\section{Abbreviations \\ BBB: Blood-brain barrier; CT: Computed tomography; DWl: Diffusion weighted imaging; FLAIR: Fluid attenuated inversion recovery; LDH: Lactate dehydrogenase; MAP: Mean arterial pressure; MRI: magnetic resonance imaging; PRES: Posterior reversible encephalopathy syndrome; RCVS: Reversible cerebral vasoconstriction syndrome; SAH: Subarachnoid hemorrhage; SWI: Susceptibility weighted imaging}

\section{Acknowledgements \\ None. \\ Funding \\ This work was supported by the National Natural Science Foundation of China (Grant No. 81401051).}

Availability of data and materials

All data related to this case report are contained within the manuscript.

\begin{abstract}
Authors' contributions
$\mathrm{DH}$ and JX have made substantial contribution to data collection. $\mathrm{DH}$ and $\mathrm{YZ}$ were responsible for data analysis and interpretation and manuscript revision. ZZ drafted the manuscript and made substantial contribution to manuscript revision. All the authors have read and approved the manuscript for publication and agreed to be accountable for all aspects of the work.
\end{abstract}

Ethics approval and consent to participate

Not applicable.

\section{Consent for publication}

The patient has consented to submission of this case report to the journal, and we have obtained a written informed consent.

\section{Competing interests}

The authors report no conflict of interest.

\section{Publisher's Note}

Springer Nature remains neutral with regard to jurisdictional claims in published maps and institutional affiliations. 


\section{Author details}

'Department of Neurology, Renmin Hospital of Wuhan University, Jiefang Road 238, Wuchang District, Wuhan 430060, China. ${ }^{2}$ Department of Radiology, Renmin Hospital of Wuhan University, Jiefang Road 238, Wuchang District, Wuhan 430060, China.

Received: 3 June 2018 Accepted: 21 October 2018

Published online: 03 November 2018

\section{References}

1. Bartynski WS, Boardman JF, Zeigler ZR, Shadduck RK, Lister J. Posterior reversible encephalopathy syndrome in infection, sepsis, and shock. AJNR Am J Neuroradiol. 2006;27(10):2179-90.

2. Yoon SD, Cho BM, Oh SM, Park SH, Jang IB, Lee JY. Clinical and radiological spectrum of posterior reversible encephalopathy syndrome. J Cerebrovasc Endovasc Neurosurg. 2013;15(3):206-13.

3. Hinchey J, Chaves C, Appignani B, Breen J, Pao L, Wang A, et al. A reversible posterior leukoencephalopathy syndrome. N Engl J Med. 1996;334(8):494500.

4. Bartynski WS. Posterior reversible encephalopathy syndrome, part 1: fundamental imaging and clinical features. AJNR Am J Neuroradiol. 2008; 29(6):1036-42.

5. Sharma A, Whitesell RT, Moran KJ. Imaging pattern of intracranial hemorrhage in the setting of posterior reversible encephalopathy syndrome. Neuroradiology. 2010;52(10):855-63.

6. Coenen F, Duprez T, Hantson P. Concomitant occurrence of posterior reversible encephalopathy syndrome and non-convexal subarachnoid haemorrhage in a renal transplant patient. Acta Neurol Belg. 2014;114(2): 159-61.

7. Fugate JE, Rabinstein AA. Posterior reversible encephalopathy syndrome: clinical and radiological manifestations, pathophysiology, and outstanding questions. Lancet Neurol. 2015;14(9):914-25.

8. Bartynski WS. Posterior reversible encephalopathy syndrome, part 2: controversies surrounding pathophysiology of vasogenic edema. AJNR Am J Neuroradiol. 2008;29(6):1043-9.

9. Benyo DF, Smarason A, Redman CW, Sims C, Conrad KP. Expression of inflammatory cytokines in placentas from women with preeclampsia. J Clin Endocrinol Metab. 2001;86(6):2505-12.

10. Aird WC. The role of the endothelium in severe sepsis and multiple organ dysfunction syndrome. Blood. 2003;101(10):3765-77.

11. Bartynski WS, Boardman JF. Distinct imaging patterns and lesion distribution in posterior reversible encephalopathy syndrome. AJNR Am J Neuroradiol. 2007;28(7):1320-7

12. Hefzy HM, Bartynski WS, Boardman JF, Lacomis D. Hemorrhage in posterio reversible encephalopathy syndrome: imaging and clinical features. AJNR Am J Neuroradiol. 2009;30(7):1371-9.

13. Mayama M, Uno K, Tano S, Yoshihara M, Ukai M, Kishigami Y, et al. Incidence of posterior reversible encephalopathy syndrome in eclamptic and patients with preeclampsia with neurologic symptoms. Am J Obstet Gynecol. 2016;215(2):239 e1-5.

14. McKinney AM, Short J, Truwit CL, McKinney ZJ, Kozak OS, SantaCruz KS, et al. Posterior reversible encephalopathy syndrome: incidence of atypical regions of involvement and imaging findings. AJR Am J Roentgenol. 2007; 189(4):904-12.

15. Li R, Mitchell P, Dowling R, Yan B. Is hypertension predictive of clinical recurrence in posterior reversible encephalopathy syndrome? J Clin Neurosci. 2013;20(2):248-52.

16. Burnett MM, Hess CP, Roberts JP, Bass NM, Douglas VC, Josephson SA Presentation of reversible posterior leukoencephalopathy syndrome in patients on calcineurin inhibitors. Clin Neurol Neurosurg. 2010;112(10):88691.

17. Fugate JE, Claassen DO, Cloft HJ, Kallmes DF, Kozak OS, Rabinstein AA. Posterior reversible encephalopathy syndrome: associated clinical and radiologic findings. Mayo Clin Proc. 2010;85(5):427-32.

18. Liman TG, Bohner G, Heuschmann PU, Endres M, Siebert E. The clinical and radiological spectrum of posterior reversible encephalopathy syndrome: the retrospective Berlin PRES study. J Neurol. 2012;259(1):155-64.

19. Aranas RM, Prabhakaran S, Lee VH. Posterior reversible encephalopathy syndrome associated with hemorrhage. Neurocrit Care. 2009;10(3):306-12.

20. Voetsch B, Tarlov N, Nguyen TN, DeFusco C, Barest GD, Norbash A, et al. Asymmetric posterior reversible encephalopathy syndrome complicating hemodynamic augmentation for subarachnoid hemorrhage-associated cerebral vasospasm. Neurocrit Care. 2011;15(3):542-6.

21. Giraldo EA, Fugate JE, Rabinstein AA, Lanzino G, Wijdicks EF. Posterior reversible encephalopathy syndrome associated with hemodynamic augmentation in aneurysmal subarachnoid hemorrhage. Neurocrit Care. 2011;14(3):427-32

22. Cappelen-Smith C, Calic Z, Cordato D. Reversible cerebral vasoconstriction syndrome: recognition and treatment. Curr Treat Options Neurol. 2017;19(6):21.

23. Alhilali LM, Reynolds AR, Fakhran S. A multi-disciplinary model of risk factors for fatal outcome in posterior reversible encephalopathy syndrome. J Neurol Sci. 2014:347(1-2):59-65.
Ready to submit your research? Choose BMC and benefit from:

- fast, convenient online submission

- thorough peer review by experienced researchers in your field

- rapid publication on acceptance

- support for research data, including large and complex data types

- gold Open Access which fosters wider collaboration and increased citations

- maximum visibility for your research: over $100 \mathrm{M}$ website views per year

At BMC, research is always in progress.

Learn more biomedcentral.com/submissions 